\title{
DE LA DESTERRITORIALIZACIÓN A LA RETERRITORIALIZACIÓN EN EL ACCESO, USO Y REGULACIÓN DE RECURSOS SOCIO-AMBIENTALES: CASO DE LAS PROVINCIAS DE ALMEIDAS Y SABANA CENTRO (CUNDINAMARCA, COLOMBIA)*
}

\author{
FROM DETERRITORIALIZATION TO RETERRITORIALIZATION IN \\ THE ACCESS, USE AND REGULATION OF SOCIO-ENVIRONMENTAL \\ RESOURCES: THE CASE OF ALMEIDAS AND SABANA CENTRO PROVINCES \\ (CUNDINAMARCA, COLOMBIA)
}

Manuel Enrique Pérez-Martínez**

\section{Resumen}

Objetivo. Interpretar las proyecciones de agentes sociales, que desde la escala local, plantean la necesidad de constituir pactos territoriales que contrarresten los conflictos por el acceso, uso y regulación de recursos socio-ambientales. Metodología. Se aplicó un ejercicio de georreferenciación de cuencas y explotaciones mineras en la zona de estudio, además de etnografia proyectual a 30 personas provenientes del sector público, organizaciones ambientales y de pequeños agricultores. Resultados. El caso revela altos grados de distorsión en el acceso, uso y regulación de recursos socio-ambientales, asunto que corresponde a la dispersión y limitadas opciones de solución de los agentes institucionales públicos y privados responsables. Conclusiones. La interpretación de procesos territoriales que surgen al margen de la escala estrictamente sectorial, reconoce en el sustrato empírico de las redes sociales, la posibilidad de instaurar proyectos que mitiguen las condiciones de conflictividad socio-ambiental que producen en la escala local los efectos del cambio socio-económico global.

Palabras clave: territorio, conflicto socio-ambiental, agenciamiento local, redes sociales, pactos territoriales.

\footnotetext{
* Este artículo presenta aplicaciones conceptuales y metodológicas que se adelantan en la investigación doctoral que el autor lleva a cabo en el Doctorado sobre Estudios Territoriales de la Universidad de Caldas, bajo la dirección de las doctoras Beatriz Nates Cruz de la Universidad de Caldas (Manizales, Colombia) y María Geralda de Almeida de la Universidad Federal de Goiás (Brasil). Para el desarrollo del trabajo de campo se obtuvo apoyo de la Corporación Autónoma Regional de Cundinamarca; los resultados obtenidos han contribuido a la realización de acciones de gestión social de la institución para la mitigación de los conflictos socio-ambientales en la zona de estudio.

*** Pontificia Universidad Javeriana. Bogotá, Colombia. E-mail: manuel.2511213267@ucaldas.edu.co -

(D) orcid.org/0000-002-1033-0287. Google Scholar
} 
De la desterritorialización a la reterritorialización en el acceso, uso y regulación de recursos socio-ambientales...

\begin{abstract}
Objective. To interpret the projections of social agents who, from the local scale, raise the need to establish territorial agreements that counteract conflicts over the access, use and regulation of socio-environmental resources. Methodology. An exercise in the georeferencing of basins and mining exploitation in the study area was applied, as well as project ethnography to 30 people coming from the public sector, environmental organizations and small-scale farmers. Results. The case reveals a high degree of distortion in the access, use and regulation of socio-environmental resources, a matter that corresponds to the dispersion and limited options for solution from the responsible public and private institutional agents. Conclusions. The interpretation of territorial processes that arise apart from the strictly sectoral scale, recognizes the possibility of establishing projects that mitigate the socio-environmental conflict conditions that produce, at the local scale, the effects of the global socio-economic change in the empirical substratum of social networks.
\end{abstract}

Key words: territory, socio-environmental conflict, local management, social networks, territorial agreements.

\title{
Introducción
}

En razón a los planteamientos de Strange (1996), las sociedades delTercer Mundo se encuentran atrapadas en una profunda transformación de actividades económico-productivas y extractivas que han subordinado las políticas estatales a las disposiciones que impone el libre mercado, condición que ha hecho imperiosa la necesidad de integrar territorios al mercado mundial, obedeciendo a la anarquía y aceleramiento de la competencia capitalista y al interés de grupos económicos transnacionales.

Se surte aquí la evidente tendencia del modelo económico neoclásico que separa su razonamiento del mundo físico natural, ruptura epistemológica que supuso desplazar la idea de sistema económico - con su carrusel de producción, consumo y crecimiento- al campo del valor. De esta forma, aparece un sistema de explotación y producción regido bajo parámetros netamente monetarios. Este asunto da paso a una "orientación económica que se desentiende del mundo físico, sin dar cuenta de las irreversibilidades o pérdidas de calidad del entorno social y natural" (Naredo, 2010, p. 8).

Esta orientación económica revela la injerencia de la extracción y del manejo de los recursos socio-ambientales, pero no su reposición, asunto que termina con el deterioro manifiesto de desigualdades territoriales, lo que ocasiona conflictos que intrínsecamente se sustraen de profundas contradicciones de orden económico y político. 
Como lo ejemplifica Naredo (2010):

\begin{abstract}
(...) tal es el caso de una empresa minera, que amplía la producción -léase extracción- de minerales a costa de reducir las reservas que pueden ser apropiadas y valoradas, pero no producidas. O de la construcción de edificios que exige la ocupación de suelo fértil. O de la empresa que produce utilizando y contaminando el aire, que no está ni apropiado ni valorado. (p. 10,11)
\end{abstract}

En este sentido, el medio físico natural es fragmentado y recodificado por la economía como elemento del capital globalizado, operación hermenéutica que bajo las consideraciones de Leff (2004) plantea la unificación de los paradigmas de la economía y de la ecología, así como de las diferentes cosmovisiones y significaciones culturales donde se han desarrollado saberes sobre la vida y la producción.

En definitiva, podemos afirmar que la injerencia e implicaciones de los signos económicos del modelo global determinan la desterritorialización y reterritorialización de amplios sectores de las relaciones sociales a escala mundial que inciden en la escala local o, lo que es lo mismo, componen la multiplicación e intensificación de relaciones sociales expresadas a través de flujos, redes y transacciones.

Juegan en estas circunstancias retos interpretativos que posibiliten argumentar las implicaciones territoriales que en este argumento manifiestan las conflictividades socio-ambientales inherentes. No obstante, a las alternativas que desde el agenciamiento local pueden viabilizar la sostenibilidad de los recursos socio-ambientales, sólo si se reproducen ingentes procesos de participación e interacción entre los diversos actores implicados. Las evidencias que aquí se exponen pretenden dar reconocimiento a las posibilidades de definir una figura de Pactos Territoriales que mitigue y defina alternativas, a fin de contrarrestar las condiciones económicas globales en el acceso, uso y regulación de los recursos socio-ambientales en espacios geográficos específicos.

\title{
Discusión
}

Los conceptos que orientaron el estudio intentan articular en un ámbito explicativo la noción de territorio, partiendo de los aportes de Abramovay (2003, 2006), quien lo incorpora y asume a la economía y la sociología a partir de cuatro dimensiones: 1) El territorio invita a que se abandone el horizonte estrictamente sectorial. Dimensión que tiene dos consecuencias: desde lo operativo, exige refinamiento de los instrumentos estadísticos que lo delimitan; la otra es de naturaleza teórica: los territorios no se definen por límites físicos, sino por la manera como se produce en su interior la interacción social. 2) La segunda virtud de la noción de territorio es 
De la desterritorialización a la reterritorialización en el acceso, uso y regulación de recursos socio-ambientales...

que ella impide la confusión entre crecimiento económico y proceso de desarrollo. La pobreza rural, por ejemplo, no puede ya ser interpretada como simple expresión de insuficiencia en la renta, sino como un fenómeno multidimensional. 3) De esta manera, el estudio empírico de los actores y de sus organizaciones se vuelve absolutamente crucial para comprender situaciones localizadas. 4) Finalmente, el territorio enfatiza la manera como una sociedad utiliza los recursos de los que dispone en su organización productiva y, por tanto, en la relación entre sistemas sociales y ecológicos.

Para avanzar en su interpretación, el concepto de territorio expresa tres supuestos, a partir de los estudios de Haesbaert (2011), Raffestin (2011) y Mançano (2014): 1) Es un espacio controlado y delimitado, en el cual se ejerce poder y se reproducen conflictos, en tanto redes de relaciones de control de flujos que regulan la circulación de las personas, bienes y recursos. 2) Representa la integración explicativa entre aquellos elementos físicos, geográficos y sociales, le da vida a la territorialidad. Asunto que se reproduce mediante la acción social intencional orientada a dirigir, influenciar o controlar las personas. 3) Se asume desde una perspectiva integradora y contenedora del medio natural, el cual se reproduce históricamente con base en el conflicto y por la apropiación económica, cultural y política del espacio.

En este sentido, afirmamos con Pérez (2011) que el territorio se articula a un ámbito explicativo multidimensional, que se concibe como un escenario de vinculaciones, pactos, alianzas y negociaciones permanentes que se originan por diversas formas de acción colectiva, las cuales dependen sustancialmente de procesos de activación y canalización de fuerzas sociales, de avance a la capacidad participativa, la asociativa, la cooperación y la sostenibilidad de los recursos naturales; así como de la iniciativa e innovación constante de los agentes institucionales que cohabitan y dirigen los destinos de un espacio geográfico en particular.

Dicho sea de paso, el sentido propio de la noción de territorio a la que aquí hemos aludido, contiene en su configuración procesos de conflictividad, generados por la pugna entre diferentes acciones de integración o reproducción territorial. Los conflictos deben observarse como fenómenos sociales dinámicos que se desarrollan en el tiempo y tienen lugar en el ámbito de la construcción de lo público (Walter, 2009).

Los conflictos asociados a procesos territoriales de acceso, uso y regulación de recursos socio-ambientales - por ejemplo- tienen que ver con enfrentamientos, diferencias, fricciones, posiciones antagónicas o contiendas entre dos o más partes respecto a las dinámicas de apropiación, uso, control, y distribución de recursos naturales abundantes, escasos o valiosos, por lo cual estas dinámicas de enfrentamiento y sus resultados tienen una clara expresión en el territorio y afectan de una u otra manera su configuración armónica o inarmónica, en términos de propiciar procesos ya sea no resilientes y depredadores o procesos sostenibles de uso y manejo desde todas las perspectivas. Muchos recursos naturales tienen características 
de recursos de uso común, y frente a la ausencia de normas consensuadas aplicadas y eficientes de uso y protección puede ocasionarse la denominada "Tragedia de los Comunes", es decir enfrentar un destino de irreversible deterioro y destrucción con graves implicaciones para la continuación de las actividades de producción y reproducción de sus pobladores (Ostrom, 2000; López, 2008).

Folchi (2001), establece que el conflicto socio-ambiental se genera:

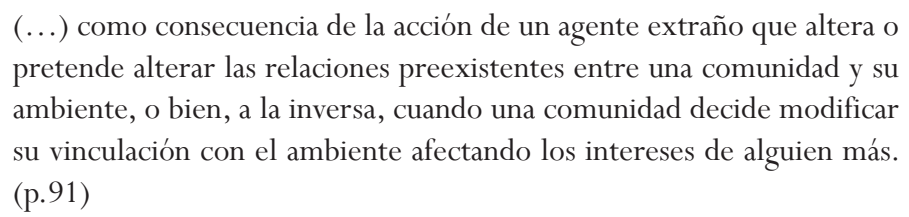

En otros términos, este tipo de conflicto se produce por intervención humana y adopción de sistemas tecnológicos en los procesos de apropiación y transformación de la naturaleza, por lo que requiere del diálogo y búsqueda de acuerdo e intereses comunes y solución.

Los conflictos socio-ambientales, también denominados "redistributivos", se refieren a procesos sociales de enfrentamiento que emergen por desacuerdos, disputas o denuncias con respecto a las formas como se distribuyen los costos y beneficios de las dinámicas de apropiación, distribución, control y uso de los recursos naturales de un territorio. También denominado "ecologismo de los pobres", busca visibilizar las maneras en que proyectos de construcción de infraestructura, productivos y extractivos (mineros, hidroenergéticos), destruyen los medios de vida de los cuales dependen las comunidades locales (agua, bosque, pesca, suelo, fauna, flora, etc.) siendo además estas receptoras de la mayoría de los impactos negativos de los proyectos, mientras el grueso de los beneficios son apropiados por actores externos.

No obstante, muchos conflictos socio-ambientales se originan no sólo por la puesta en marcha de los proyectos (productivos, de infraestructura, extractivos, etc.) enumerados más arriba, sino que además emergen como consecuencia de intervenciones gubernamentales de distintos tipos, usualmente dirigidas al desarrollo (ordenamiento territorial, leyes, normas, etc.), los cuales son agravados en situaciones y contextos de pobreza e inequidad lo que produce impactos negativos en la calidad de vida de la población (ruido, malos olores, emisiones, vertimientos, residuos sólidos, deforestación, fragmentación de hábitats, pérdida de biodiversidad, deterioro de la calidad del paisaje, reducción y desaparición de fuentes hídricas, de espacios de recreación, de fauna y flora emblemática, y procesos generalizados de contaminación de los biomas agua, aire, bosque, etc.). 
De la desterritorialización a la reterritorialización en el acceso, uso y regulación de recursos socio-ambientales...

Estas dinámicas y procesos además tienden a producir efectos negativos, costosos, complejos y acumulados en el tiempo sobre la población y el territorio (por ejemplo sobre la salud, sobre la posibilidad de caer en la trampa de la pobreza, escasez y, en algunos casos, son la semilla de conflictos violentos). En últimas, deterioran la calidad de todos los recursos presentes en el territorio (sociales, humanos, físicos, financieros, etc.), y amenazan con la probabilidad de mantener unas características económicas, naturales, sociales y humanas suficientes para la supervivencia.

Dicho marco interpretativo es connotado en su reproducción por un campo de relaciones de poder y generación de asimetrías. En otros términos, se asume aquí como un proceso interactivo entre agentes sociales que movilizan intereses compartidos y generan de forma simultánea la integración de la actividad económica, la preservación ambiental, las preocupaciones sociales así como la búsqueda de sistemas eficientes de gobernabilidad. Por ello, asumimos en este estudio las asimetrías socio-ambientales, producto de la injerencia del modelo global de desarrollo, como una forma de creación social y cultural que puede modificarse según como se aborde por los agentes sociales y se los conduzca, a fin de articular actitudes e intereses entre las partes en disputa.

Factores de creación social que están mediados por formas de agenciamiento local que se determinan por la liberación de acciones y movimientos de agentes sociales que hilvanan estrategias (planes), y que mediante alianzas o pactos territorializan o desterritorializan sus intereses (Deleuze y Guattari, 2004). Acciones individualizadas, sin un centro difusor, pero afirmativamente interactuando a través de diversas áreas, redes, nodos y vinculaciones que determinan un nuevo campo de territorialidades, más o menos contrastadas pero ensambladas funcionalmente (Giddens, 2003).

Se adicionan a estas nociones los criterios de la sostenibilidad socio-ambiental que desde los años 80 se asumen como una condición básica para el desarrollo, la cual expresa una perspectiva holística e integradora que hace evidente el marco de relaciones entre sistemas (socioeconómicos, tecnológicos, culturales y ambientales, entre otros), dinámica de procesos (energía, materia e información) y escala de valores (bioéticos, ideas, etc.). Sin embargo, es conveniente resaltar que la sostenibilidad para el desarrollo se entiende desde lo conceptual y estratégico, como un proceso de cambio, adaptación, auto-organización y equilibrios permanentes para ajustar las relaciones de los sistemas ecológicos, económicos y sociales dentro de un sistema global. En este sentido, afirma Jiménez (2002), que para implementar esquemas de sostenibilidad no sólo es obligatorio mantener la capacidad de los ecosistemas naturales, sino que además es prioritario promover habilidades en los sistemas humanos para la creación de dispositivos de sustentación social, económica e institucional que sean competentes e idóneos para potenciar su auto-organización y su pleno funcionamiento adaptativo. 
Por lo tanto, acogemos la sostenibilidad de los procesos territoriales como un producto de múltiples variables, que de manera sistémica integran un conjunto de escalas y valores interdependientes, cuya aplicabilidad plena requiere de un cúmulo amplio de actuaciones, comportamientos locales que propendan por la participación, la integración y trabajo en equipo de los diversos sectores (ciudadanos, organismos gubernamentales locales, regionales y nacionales, organizaciones sociales, ambientalistas y no gubernamentales, instituciones educativas, sector productivo, etc.) de una comunidad para participar activamente en su desarrollo.

Por consiguiente, aquí la participación se entiende como aquel procedimiento de reconocimiento, representación e inclusión amplia y permanente de agentes sociales estratégicos, en la gestión de estrategias territoriales como eje fundamental de la democracia y, por ende, es el espíritu de cualquier proceso de desarrollo (Sepúlveda, 2008).

En este orden de ideas, se hace de vital importancia avanzar hacia la materialización de pactos territoriales, basados en la interacción y relacionamiento de redes sociales, entendidas aquí como una manera de proceder socialmente y de responder a una intención específica de intervención para mejorar las condiciones de vida de una comunidad social específica. Conforme a ello, se asume por red social el conjunto bien definido de actores, individuos, grupos, organizaciones, comunidades, sociedades globales, etc., que están vinculados entre sí mediante un conjunto de relaciones sociales (Borgatti, 2003).

En consecuencia, a esta contribución social instaura en la práctica fuerzas generadoras de discursos, enfoques y diseño de programas y proyectos, que podrían estar dando lugar incluso a una variedad de vínculos sociales que se expresan mediante pactos, acuerdos de cooperación, procesos de negociación en diferentes niveles y relaciones institucionales. De esta manera se crea un sistema abierto, multicéntrico, que tiene un intercambio dinámico entre los integrantes de un colectivo con otros colectivos, lo que conlleva a desarrollar la potencialidad de los recursos que ellos tienen y la creación de nuevas e innovadoras alternativas para la solución de problemas y la satisfacción de sus necesidades (Williner, Sandoval, Frias y Pérez, 2012).

\section{Los procesos de desterritorialización y sus implicaciones socio-ambientales}

Las provincias de Almeidas y Sabana Centro en el departamento de Cundinamarca, contienen la cuenca alta del río Bogotá, en ella se encuentran 8 municipios: Tibirita, Machetá, Manta, Chocontá y Villapinzón pertenecientes a la cuenca del río Machetá; Guatavita correspondiente a la cuenca del río Guachetá; y Suesca y Sesquilé pertenecientes a la subcuenca alta del río Bogotá (Figura 1). Esta provincia tiene una extensión de 147.500 y cuenta con un total de 81.321 habitantes (CAR, 2011). 
De la desterritorialización a la reterritorialización en el acceso, uso y regulación de recursos socio-ambientales...

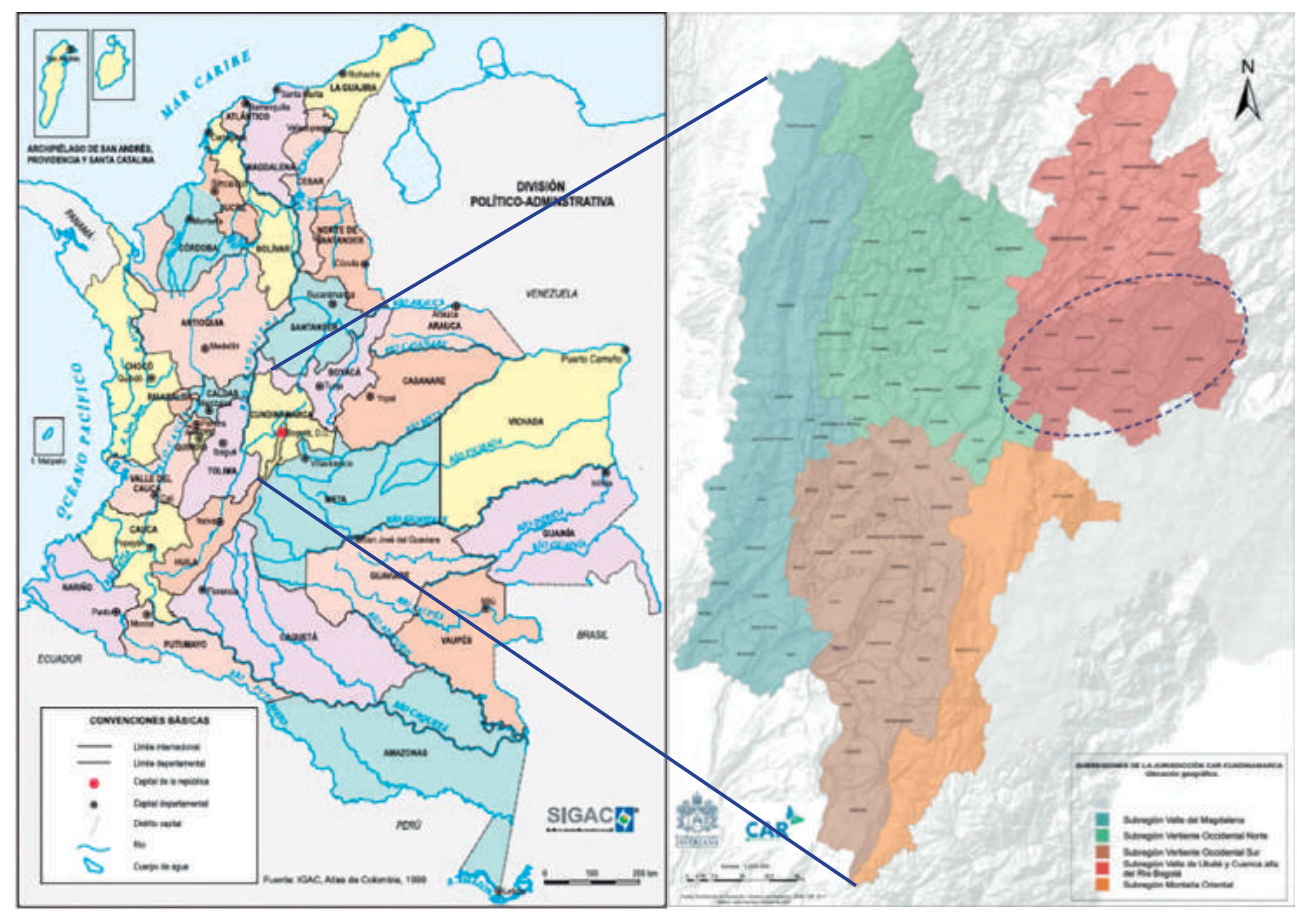

Fuente: esta investigación a partir de datos cartográficos suministrados por la Corporación Autónoma Regional de Cundinamarca y del Instituto Geográfico Agustín Codazzi (IGAC. 2007).

Figura 1. Localización de las provincias de Almeidas y Sabana Centro. (Ubicación geográfica en Colombia)

\section{Componente biofísico}

Las provincias están constituidas por tres cuencas hidrográficas (Figura 2), las cuales están compuestas por los ríos: Machetá, con un área total de $2.508 \mathrm{~km}^{2}$ de extensión, presenta un área de drenaje de 508,7 km²; Gachetá, la cual posee un área de $1.716 \mathrm{~km}^{2}$ y una extensión de $97 \mathrm{~km}^{2}$; Bogotá que presenta una superficie total de $5.671 \mathrm{~km}^{2}$, conformada por 19 subcuencas de tercer orden, recorre un total de 308 km desde su nacimiento en Villapinzón a 3.300 msnm hasta su desembocadura al río Magdalena a 208 msnm en Girardot. Presenta una aptitud y uso del suelo correspondiente a $45,4 \%$ de uso agropecuario y $46,8 \%$ para protección-producción (CAR, 2006-2007). 


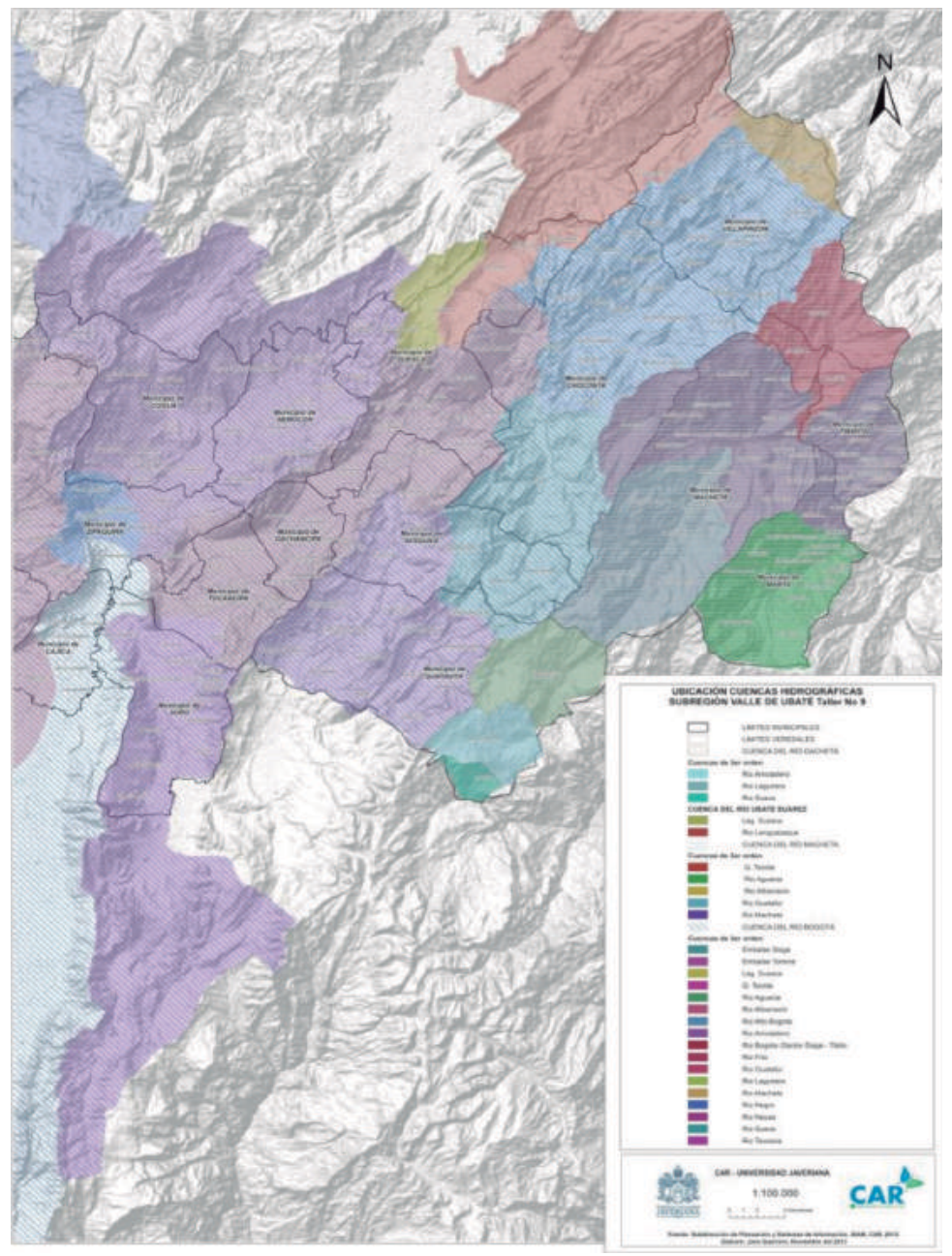

Fuente: esta investigación a partir de georreferenciación de la zona de estudio.

Figura 2. Cuencas y subcuencas pertenecientes a las provincias de Almedias y Sabana Centro.

\section{Componente socioproductivo}

Las provincias de Almeidas y Sabana Centro se caracterizan por concentrar sus actividades productivas en los siguientes reglones: 
De la desterritorialización a la reterritorialización en el acceso, uso y regulación de recursos socio-ambientales...

En el sector floricultor representa el 75\% de la producción nacional, siendo el principal empleador en la Sabana de Bogotá, actividad concentrada para estas provincias principalmente en el municipio de Tocancipá (CAR, 2012).

Por su parte, el sector papicultor es desarrollado bajo el esquema de economía campesina con predominio de agricultores minifundistas, se destacan los municipios de Zipaquirá, Chocontá y Villapinzón, por lo que la participación de Cundinamarca en la producción nacional es del $3,79 \%$. El principal daño ambiental se da debido a que es un sistema productivo que hace uso intensivo de fertilizantes y plaguicidas con alto nivel de toxicidad. Además se ha llevado a cabo en ecosistemas de páramo, lo que conlleva a la pérdida de biodiversidad (CAR, 2012).

En cuanto al sector agroindustrial, Sabana Centro constituye la tercera provincia (después de Ubaté y Chiquinquirá) en tener mayor importancia para la producción del subsector de lácteos, con alrededor del 28\% de las unidades productivas de la jurisdicción, desarrollándose principalmente en los municipios de Sopó y Cajicá, subsector caracterizado por presentar un bajo nivel de agremiación empresarial (CAR, 2012).

Otro renglón importante en la economía de la subregión es el sector industrial, principalmente por el subsector de las curtiembres, actividad productiva tradicional, desarrollada por micro y pequeñas empresas de carácter familiar. Dentro de la zona, la industria curtidora está compuesta aproximadamente por cerca de 180 unidades productivas que se concentran en los municipios de Villapinzón y Chocontá. Estas se caracterizan por no contar con un sistema básico de tratamiento de aguas residuales, por lo que sus vertimientos se convierten en una de las principales problemáticas ambientales de la subregión (CAR, 2012).

En el sector de la minería, la explotación de carbón se desarrolla principalmente en las provincias de Ubaté y Sabana Centro, y adicionalmente en esta última se presenta una producción de arcilla, orientada al sector de la construcción, dada una alta demanda de materiales de construcción para el Distrito Capital para el mantenimiento y construcción de la infraestructura y vivienda (CAR, 2012). (Ver Figura 3). 


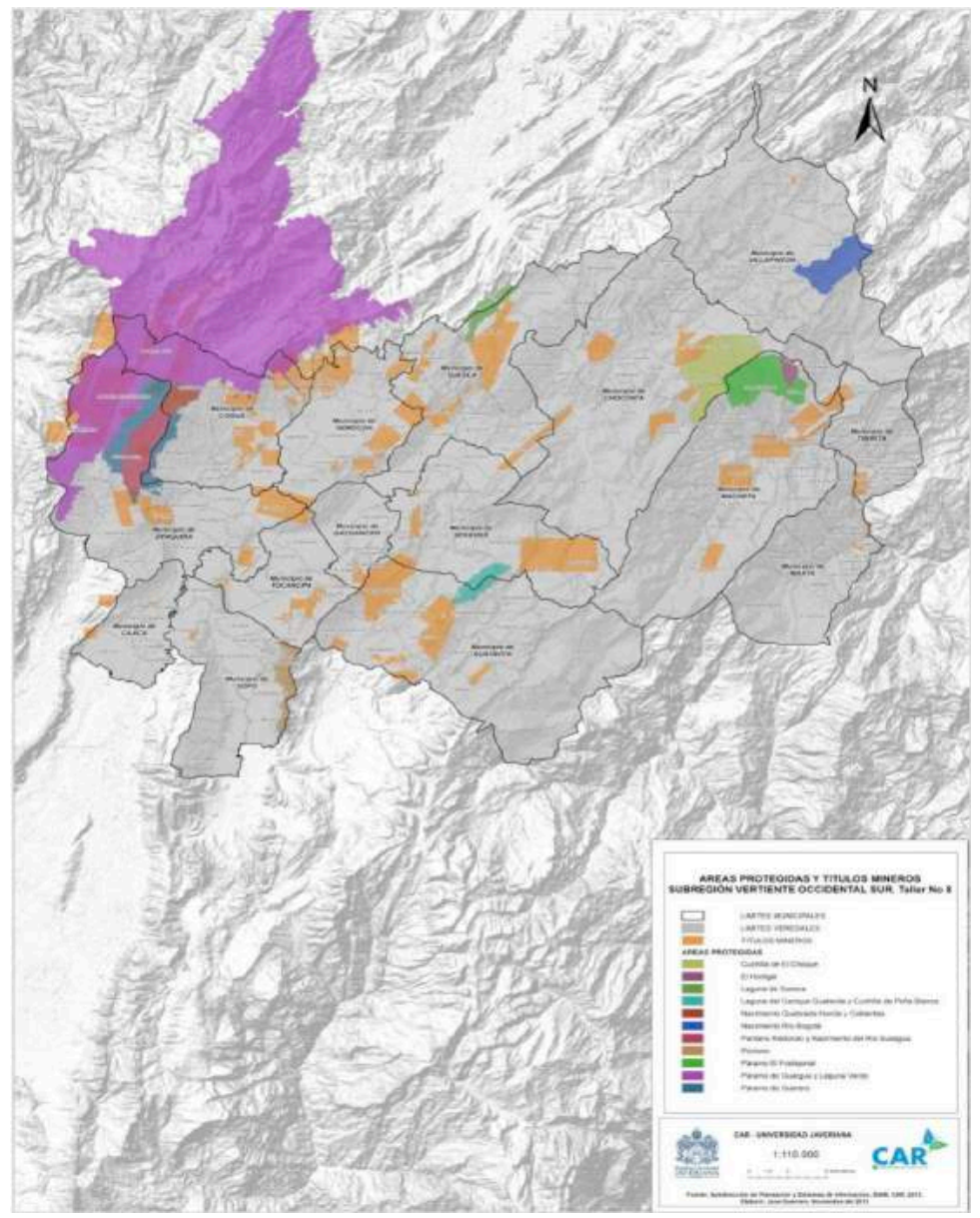

Fuente: esta investigación a partir de georreferenciación de la zona de estudio.

Figura 3. Áreas protegidas, títulos y concesiones mineras presentes en las provincias de Almeidas y Sabana Centro.

\section{Implicación del desarrollo productivo en la territorialización de los conflictos socio-ambientales}

Dentro de los conflictos con mayor grado de desequilibrio se encuentran aquellos relacionados con la calidad alimentaria, pues se reconoce que en la subregión no hay posibilidades de desarrollar cultivos orgánicos que eliminen el uso de agroquímicos, debido a la excesiva contaminación del suelo y el agua, y a los vertimientos de tóxicos por la extracción minera. 
De la desterritorialización a la reterritorialización en el acceso, uso y regulación de recursos socio-ambientales...

De este modo, la mala disposición de dichos desechos es otro problema que revela un estado total de desequilibrio socio-ambiental, donde no se vislumbra una gestión adecuada más allá de las acciones aisladas de algunas agremiaciones.

A continuación se presentan, en las figuras 4 y 5, las problemáticas que según la información suministrada en campo fue calificada de cero (0) a cinco (5), otorgando un valor de mayor conflictividad a los rangos tendiente a cero (0) y de menor o nula conflictividad en el rango tendiente a cinco (5).

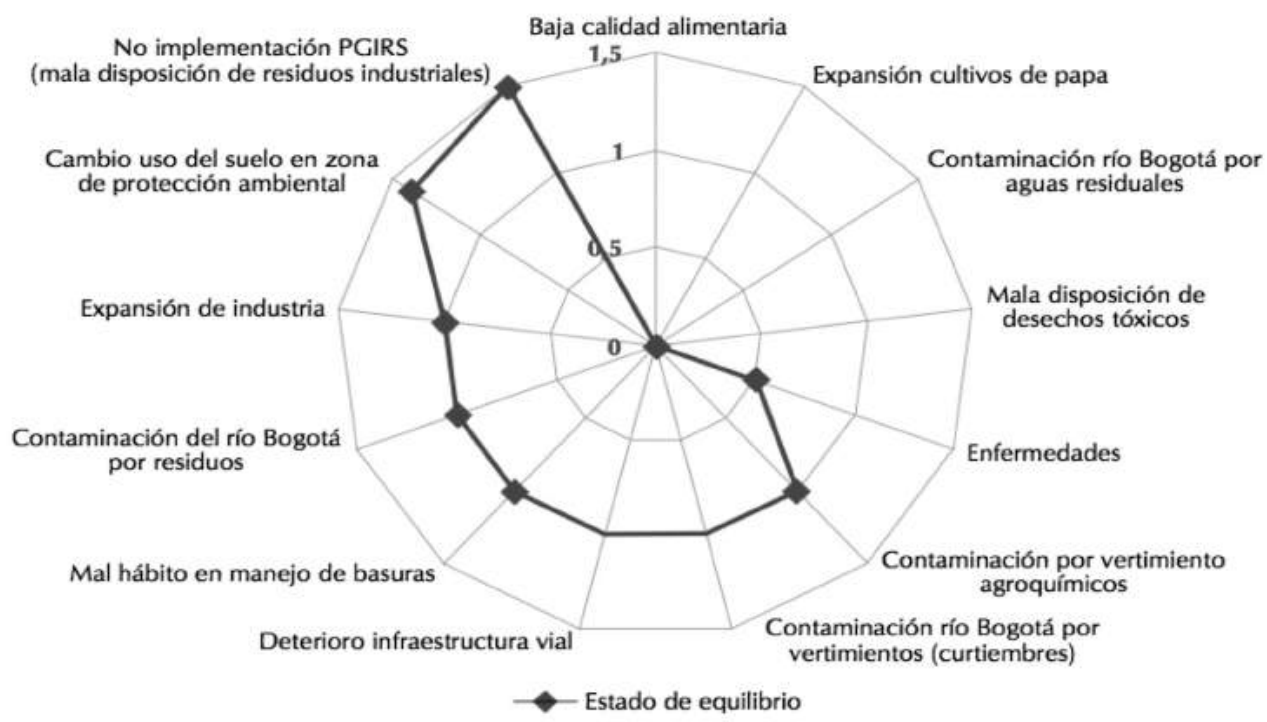

Fuente: esta investigación a partir de procesamiento de datos y digitalización en Grupo Focal de Análisis de Conflictos.

Figura 4. Conflictos socio-ambientales, provincia de Almeidas. 


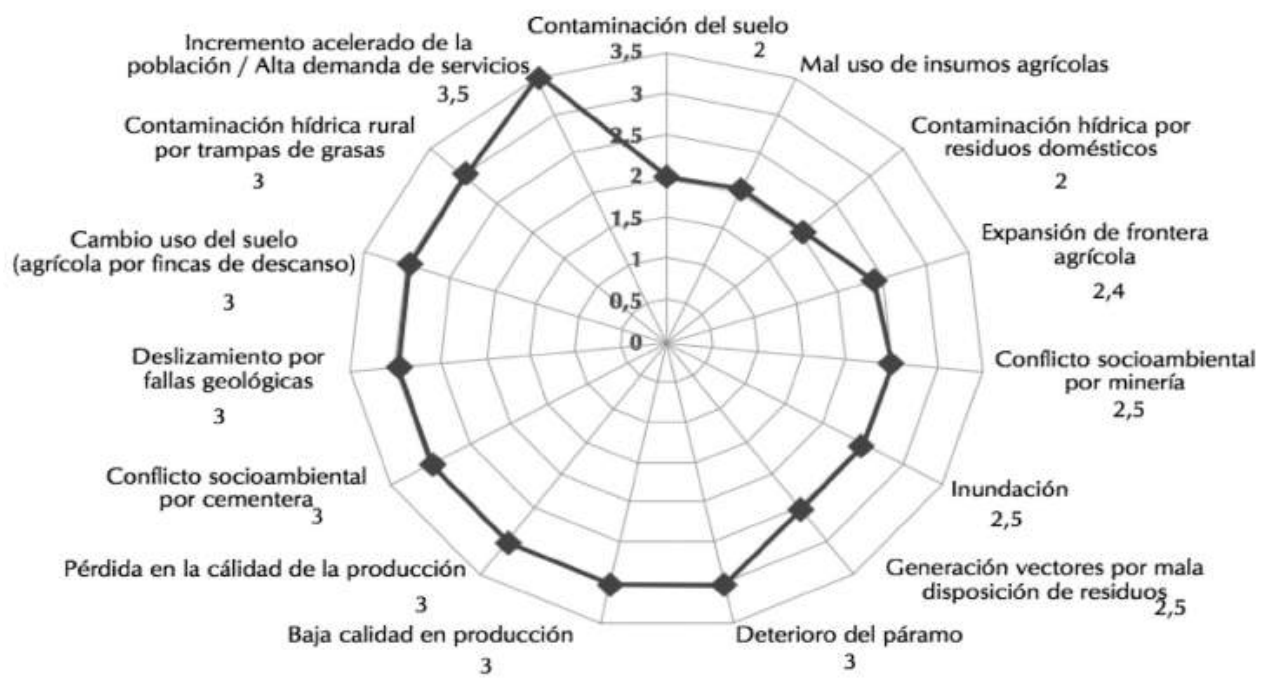

Fuente: esta investigación a partir de procesamiento de datos y digitalización en Grupo Focal de Análisis de Conflictos.

Figura 5. Conflictos socio-ambientales, provincia Sabana Centro.

Los conflictos territoriales referidos a la industria minera, tanto de carbón como de las cementeras, se asumen por sus pobladores en tanto que:

la aceptación por parte de la comunidad es estar estática, pues no tienen cómo pelear ante eso, los bajos costos en mano de obra al usar a los mismos campesinos, se venden terrenos, se ven muchas explotaciones artesanales, hasta ahora se está tecnificando y hay migración de los campesinos porque el suelo se va hundiendo y hace que hayan derrumbes y problemas en las viviendas. (Inger Xiomara Ordóñez, comunicación personal, 18 y 19 de julio de 2015)

En la zona por parte de la cementera el municipio que más sufre es Suesca, se perdió la identidad de las rocas de escalada que era su parte turística y la parte visual, la cementera dañó todo (...) se han hecho protestas, peticiones a la Personería para que les ayuden a ver cómo se puede hacer, cabildos abiertos y solicitudes a la CAR de por qué ese permiso y dejaron que la cementera invadiera el espacio urbano. (Camilo Ruiz, comunicación personal, 18 y 19 de julio de 2015) 
De la desterritorialización a la reterritorialización en el acceso, uso y regulación de recursos socio-ambientales...

Por otra parte, se discuten problemas como inundaciones, generación de vectores por mala disposición de residuos y deslizamientos por fallas geológicas que, si bien están afectando a las comunidades, corresponden a factores ambientales con posibles soluciones en lo técnico. Referente a esto se menciona:

(...) ha habido el año pasado, y este invierno inundaciones en la ronda del río Bogotá, bajando hacia Barandilla, Nemocón y Cagua, y obviamente más abajo hasta Cota hay inundaciones. (María Villamil, comunicación personal, 18 y 19 de julio de 2015)

La ubicamos en la parte de Machetá que es como la zona que más sufre por este impacto [deslizamientos] y el páramo en Cagua, a raíz del invierno fuerte que hubo en muchas áreas de las 10 veredas se presentó deslizamiento y aún hoy tenemos problemas graves. Y yendo para Pacho hay derrumbes porque ahí están las receberas. (Luis Alberto Rubiano, comunicación personal, 18 y 19 de julio de 2015)

En seguida se georreferencian, en la Figura 6, las implicaciones de aquellos conflictos territoriales a consecuencia de las dinámicas de industrialización y sus implicaciones a escala veredal: 


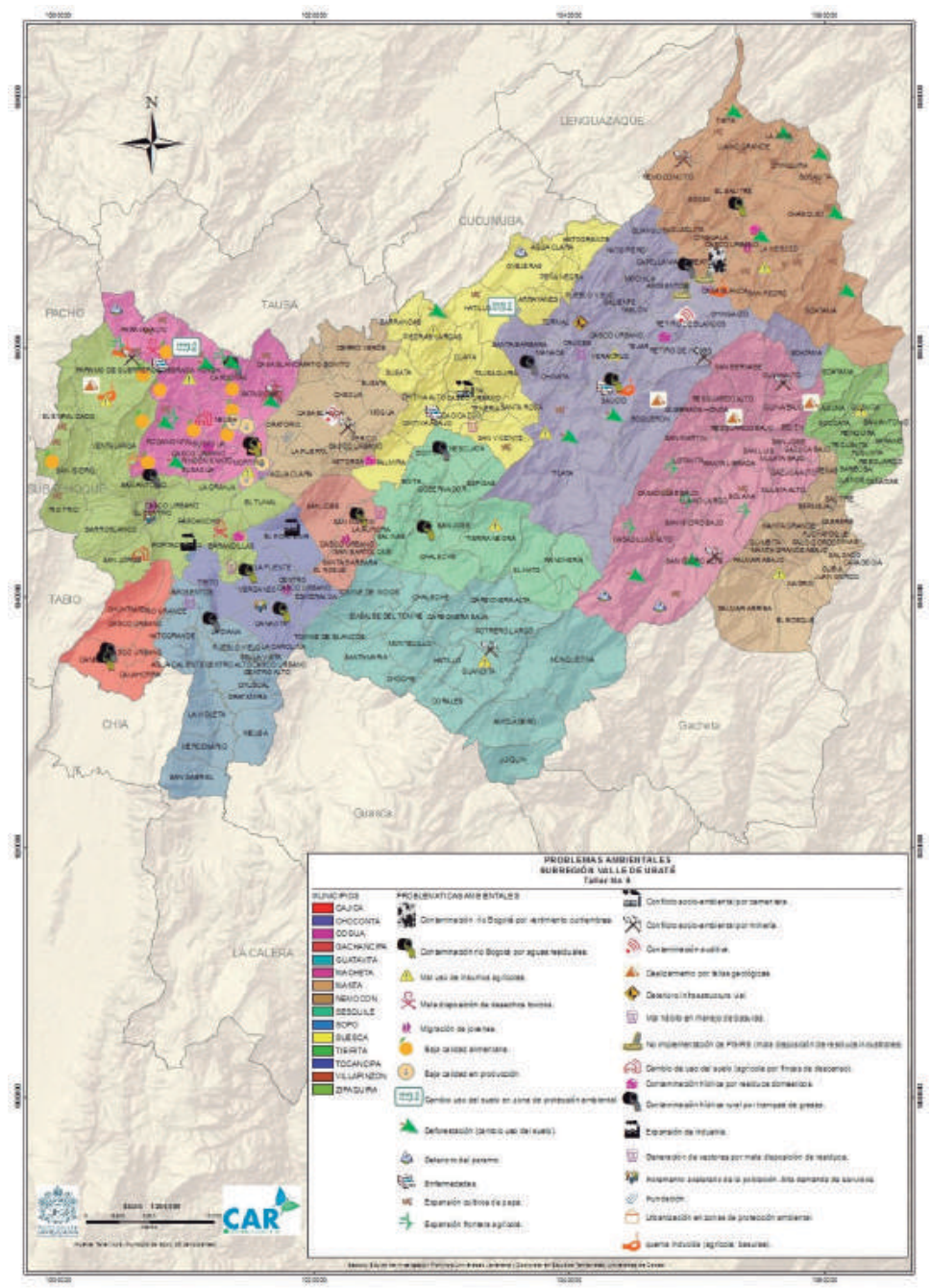

Fuente: esta investigación a partir de digitalización de Grupo Focal de Cartografía Social.

Figura 6. Georreferenciación de los conflictos socio-ambientales en las provincias de Almeidas y Sabana Centro.

En síntesis y con base en los relatos de los actores locales implicados, se pueden definir cinco escenarios de reproducción de los conflictos, los cuales tienden a manifestar un amplio distanciamiento entre las decisiones públicas, las asimetrías de los intereses privados y un notorio marco de indiferencia frente a las acciones colectivas de participación e inclusión: 
De la desterritorialización a la reterritorialización en el acceso, uso y regulación de recursos socio-ambientales...

1. No existen mecanismos permanentes para la adopción de decisiones de forma participativa, y no se fomenta la participación de los colectivos significativos para resolver los conflictos.

2. Existen mecanismos permanentes para la adopción de decisiones de forma participativa, pero restringidos únicamente a algunas que afectan al territorio.

3. El territorio se muestra inviable por sus grados de conflictividad y se corresponde con un mayor número de dispersiones entre las entidades responsables de contribuir a la solución de los conflictos.

4. Se cuenta con la intervención de actores públicos y privados, pero con limitadas opciones en la toma de decisiones. Además de un desinterés por fomentar la constitución de alianzas público-privadas para la solución de los conflictos.

5. Se fomentan actuaciones sectoriales dispersas, basadas en intereses particulares, sin promoción a actuaciones de integración para resolver los conflictos.

\section{Las formas de agenciamiento local y las redes interinstitucionales en el territorio}

Las formas de agenciamiento local en las provincias de Almeidas y Sabana Centro se han establecido entre entidades públicas y privadas, así como en organismos vinculados a actividades de orden industrial, educativo, comunitario, agropecuario, y de las acciones ciudadanas en las veedurías ambientales.

En orden jerárquico, observamos redes sociales caracterizadas especialmente por (ver Figura 7):

1. Acercamientos de los agentes subregionales a los entes institucionales, en espera de recibir beneficios bajo condición de resolver problemas locales.

2. Respuestas o acercamientos de los entes institucionales para ofrecer programas o proyectos, sin respuesta por parte de los actores subregionales.

3. Relaciones esporádicas, de corto plazo, acciones supeditadas a trámites, expectativas y compromisos entre las partes interesadas.

4. Acciones mediadas por continuas imposiciones, desacuerdos, desconfianza, incertidumbre, falta de información, así como por un bajo reconocimiento de legitimidad entre los agentes subregionales de interacción y los entes institucionales vinculantes.

A continuación se describen, en la Figura 7, las características que tienen dichas relaciones por sectores y escalas desde lo internacional, nacional, departamental y subregional, en estas últimas incluidas las entidades municipales: 

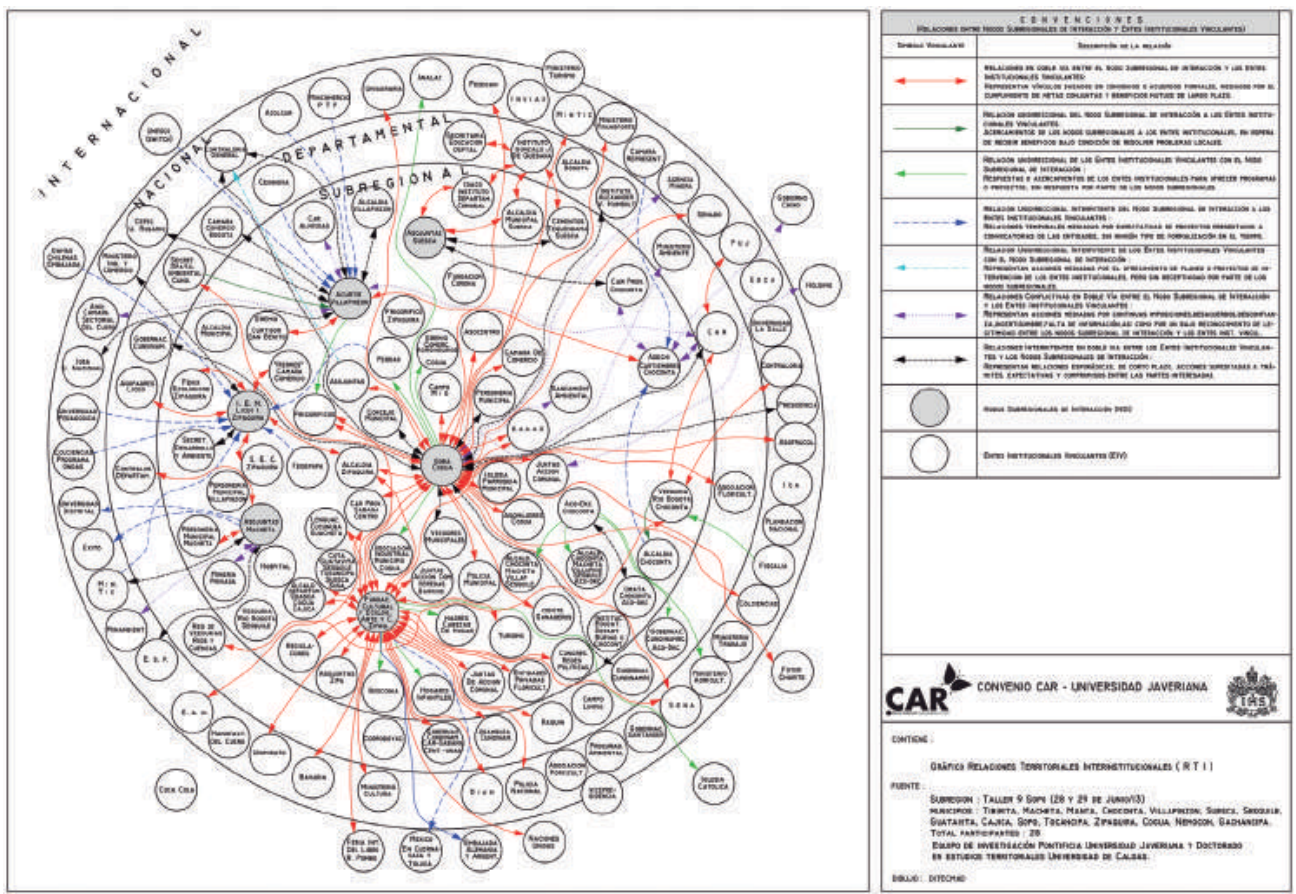

Fuente: esta investigación a partir de Grupo Focal sobre Análisis y Digitalización de Redes Sociales.

Figura 7. Redes sociales y relaciones interinstitucionales en el territorio (provincias de Almeidas y Sabana Centro).

Las formas de relacionamiento entre los agentes sociales implicados están supeditadas a diversas estrategias de interlocución y comunicación, que van desde suplir necesidades de producción agrícola, fortalecimiento de mecanismos de conservación de recursos naturales, acciones ciudadanas para el acceso a servicios públicos, hasta procesos de educación ambiental y expresión artística. Veamos en seguida los relatos que describen estas redes de interacción. Uno de los agentes generadores de las interacciones territoriales es el grupo de la Gerencia de Desarrollo Económico del municipio de Cogua, desde el cual se describe que:

en este momento, esta gerencia maneja todo lo que es la parte del sector agropecuario, atiende el emprendimiento y desarrollo empresarial, lo de turismo y comunicaciones, lo ambiental y lo del Servicio Nacional de Aprendizaje. Por eso es interdisciplinario ya que todas tienen que ver de cierto modo con alguna parte de la economía del municipio. (...) Adicionalmente, se cuenta con un municipio netamente ecológico y eso ha marcado mucho en el departamento, el tener una zona de reserva forestal. También por eso, los habitantes del municipio califican la reserva como una zona interesante dentro de toda la región. 
De la desterritorialización a la reterritorialización en el acceso, uso y regulación de recursos socio-ambientales...

Hemos hecho unos trabajos de investigación, tenemos un salón ambiental y hemos identificado zonas clave en la parte ambiental. (...) Los proyectos se manejan de manera independiente y cada municipio de acuerdo con su alcalde, y sí a este le gusta la parte ambiental, pues le va a meter toda la fuerza al asunto. Y también, de acuerdo a la categoría del municipio que pueda tener más o menos recursos para invertir en la parte ambiental. (María del Carmen Rojas, comunicación personal, 18 y 19 junio de 2015)

Esta experiencia revela un vínculo diferente e importante entre los componentes económico y ambiental; donde aparentemente la relación de productividad y conservación ha sido una relación conflictiva. Además de los aspectos ambientales, integra otras áreas que lo convierten en una forma de agenciamiento interdisciplinar, desde lo cual se plantean soluciones innovadoras para afrontar problemáticas específicas de afectación al medio ambiente.

En este escenario, también se discute a nivel local el tema de la destinación de recursos de inversión en aspectos de acceso, uso y conservación de recursos naturales, con lo cual se procuraría la unificación de presupuestos municipales en igualdad de condiciones para contrarrestar los impactos de la industrialización impuesta en el territorio. Al respecto se menciona:

(...) para nosotros lo más complejo dentro de la gerencia es poder darle a entender a los mismos profesionales que el medio ambiente está incluido en su sector. (...) En lo que tiene que ver con la asistencia técnica agropecuaria [ATA], el fuerte del municipio es la parte ganadera y la producción de leche. Nosotros a los ganaderos les ofrecemos buenas prácticas pecuarias $[\mathrm{BPP}]$ como a los porcicultores; hasta donde los recursos nos lo permiten. (Fabián Chávez, comunicación personal, 27 y 28 de junio de 2015)

Tenemos otro problema con los ganaderos, desde el punto de vista de las lecherías, debido a que ellos manejan capitales muy grandes. (...) Desde el punto de vista de los porcicultores, existe la ilegalidad en la parte de los mataderos clandestinos. (Pablo Huertas, comunicación personal, 27 y 28 de junio de 2015)

En cuanto a la avicultura, está manejada en dos formas, una que son los productores grandes y que son contaminadores a morir. Y la otra con pequeños productores, donde manejamos que la gente tenga la producción de huevo y pollo campesino. Pero nada de lo anterior se financia, se le invierten recursos locales o del Estado nacional, con eso sí podríamos equilibrarnos con el sistema, y la afectación de la industria no nos daría tan duro. (Myriam Velázquez, comunicación personal, 27 y 28 de junio de 2015) 
En lo que tiene que ver con relaciones orientadas a la conservación de los recursos naturales, con instituciones como la Corporación Autónoma Regional, encargada de otorgar licencias ambientales, la Contraloría General de la República y la Gobernación Departamental de Cundinamarca, es notorio el realce que se le ha dado a los encuentros ciudadanos, mediante mesas de trabajo comunitario en las que se disertan opiniones y se construyen acuerdos locales. Al respecto se manifestó:

en la parte ambiental tenemos un componente especial, que es la mesa del río Bogotá. La Contraloría tiene un tema específico ambiental, más allá de que cada año nos soliciten un inventario de recursos naturales, nos estaban pidiendo un Plan de Acción para que el municipio contribuya a la descontaminación del río Bogotá. Esta mesa une a todos los sectores de la cuenca alta, media y baja del río y cada dos meses nos estamos reuniendo y cada alcaldía muestra los avances en pro del río Bogotá. (Claudia Patricia Estévez, comunicación personal, 27 y 28 de junio de 2015)

La mesa ha permitido que la parte ambiental interactúe con otras Secretarías en otros municipios y antes no pasaba eso. Empezamos a trabajar con control interno, con la gerencia de infraestructura, planeación y servicios públicos y con la Secretaría Ambiental Departamental, generamos convenios. (Sonia Cruz, comunicación personal,, 27 y 28 de junio de 2015)

En una aproximación a escala local estas relaciones manifiestan otras dinámicas:

con el Concejo Municipal es intermitente y de doble vía, porque el Concejo es el que realmente define la norma interna del municipio, y ahí ellos no tienen claro lo que buscan ambientalmente en el municipio y entran a chocar con uno como técnico. (Camilo Ruiz, comunicación personal, 27 y 28 de junio de 2015)

Acorde a lo anterior, pareciera que la participación se sectoriza, se atomiza y genera mayor fragmentación. Entonces, se cuestiona ¿cuáles relaciones deberían destacarse como un vínculo de mayor relevancia en este enfoque aproximado de integralidad y en función de unos enlaces continuos y más estables para el territorio?

Para la comunidad, el sector agropecuario y el productor como actor tienen un papel determinante. De ahí nace todo y no se puede hablar de ambiente, sin hablar de personas y desarrollo. Y esa es la limitante más grande, que ambientalmente las administraciones y los entes gubernamentales gestionan el territorio y la parte biofísica de manera 
De la desterritorialización a la reterritorialización en el acceso, uso y regulación de recursos socio-ambientales...

general, la regalan a la industria de minería, y no estamos analizando de qué vive y qué come la gente. Debemos de apuntarle a la investigación, y eso es lo que está haciendo que el sector productivo nos esté cogiendo ventaja a los entes gubernamentales y a las mismas universidades. (Mauricio Torres, comunicación personal, 27 y 28 de junio de 2015)

En este orden de ideas, se conjuga la idea de incidir en procesos de gestión ambiental del territorio a partir de bases sociales, tradicionalmente apartadas del debate público. En este caso se reconoce el papel de los estudiantes y las mujeres, del énfasis prioritario en la educación ambiental, de la posibilidad de la cultura y las artes y de nuevos liderazgos locales para el cambio. Al respecto se menciona:

teníamos la Secretaría de Desarrollo Agropecuario, que sí trabajaba y que nos han prestado asesoría en semillas, eso se ha complementado con el hecho de llevar a los estudiantes a los páramos, para que vean qué es el ciclo del agua y la planta regional purificadora de agua. Entramos a la reserva, pero pienso que falta un ente que proporcione la educación; allá hay unos humedales bellísimos y están abandonados. (Ana Lucía Suspe, comunicación personal, 27 y 28 de junio de 2015)

la educación ambiental debe ser transversal y aquí no la vemos hacia fuera. Es transversal al interior de las entidades educativas; pero, no es transversal en los resultados que se pueden ofrecer para las otras entidades. “(...) No se necesita tanto proceso para relacionarse con agentes internacionales, nacionales o incluso con la academia, para el desarrollo de especificidades como las que se están planteando para el mejoramiento o la innovación de un producto” (Robinson Castro, comunicación personal, 27 y 28 de junio de 2013)

la Fundación Ecológica Cultural Arte y Ciencia que pretende hacer seres humanos más integrales, más humanos, más sensibles y que se sientan útiles a la sociedad. (Miguel Triana, comunicación personal, 27 y 28 de junio de 2015)

La mejor relación que ha tenido la Fundación es con las Madres Cabeza de Hogar, los jóvenes, los niños y niñas. La relación con ellos es porque nosotros trabajamos el medio ambiente, pero no hablamos de la parte humana, sino de ser íntegros como personas para que llegue a ser un profesional útil a la sociedad y le aporte al planeta Tierra. De ahí sale la relación con las alcaldías municipales de diferentes departamentos, pero lo más fuerte es con las del departamento de Cundinamarca, porque son los que nos ayudan y nos dan la posibilidad económica para mantenernos. (Mario Hernández, comunicación personal, 27 y 28 de junio de 2015) 
acá hay otra conexión muy importante, a raíz de esta buena relación con los jóvenes vulnerables, llegamos a las instituciones educativas con los jóvenes desescolarizados. A estos jóvenes les buscamos sus fortalezas para que haya un tejido social y ellos tienen la fortaleza de que van y educan a los niños y a los otros jóvenes en la parte ambiental, como el uso eficiente de agua y energía, separación en la fuente, y son productivos a la vez. Porque en la Fundación hay varios proyectos que son el grupo de reciclaje y el grupo pedagógico, que está conformado por mimos y está el creativo de la Fundación que escribe los libretos ambientales. (Patricia Rivera, comunicación personal, 27 y 28 de junio de 2015)

Se exaltan liderazgos con un fuerte sentido social, generadores de animación y motivación en la gestión ambiental, vinculando a ello el arte y la cultura local. Al respecto se señala:

mi liderazgo se nutre y nace debido a que yo estudié artes escénicas con Santiago García y mi trabajo fue ir a vivir en la calle del Cartucho con los niños y los jóvenes. Entonces, nació la idea de hacer una Fundación, donde los jóvenes y los niños tengan otras posibilidades, fortalecerlos y dejar huella en la vida. (Patricia Rivera, comunicación personal, 27 y 28 de junio de 2015)

Resulta que en el año 87 un día nos dio la locura por montar una obra de teatro, me tocó en la parte rural en Sesquilé, me subí en un árbol, cogí flores y se las daba a los niños y les decía que debemos cuidarlas. Yo no era ambientalista, simplemente era una teatrera. Los niños y el alcalde hicieron una evaluación diciendo ¡qué obra ambiental tan hermosa! (Patricia Rivera, comunicación personal, 27 y 28 de junio de 2015)

Es importante destacar que en ocasiones se asumen los asuntos del acceso, uso y regulación de recursos socio-ambientales de forma instrumental y dependiente de directrices que provienen de agentes externos. No obstante, ante los nuevos liderazgos de gestión local, se hacen notorias acciones innovadoras de trabajo social que posibilitan la realización de Pactos Territoriales que contrarresten las condiciones de conflictividad que se presentan en la zona. En seguida, en la Figura 8, se citan los lineamientos de mitigación que propone la comunidad consultada, sobre una priorización de los conflictos identificados: 
De la desterritorialización a la reterritorialización en el acceso, uso y regulación de recursos socio-ambientales...

\section{Ámbitos de Conflictividad Socio-Ambiental}
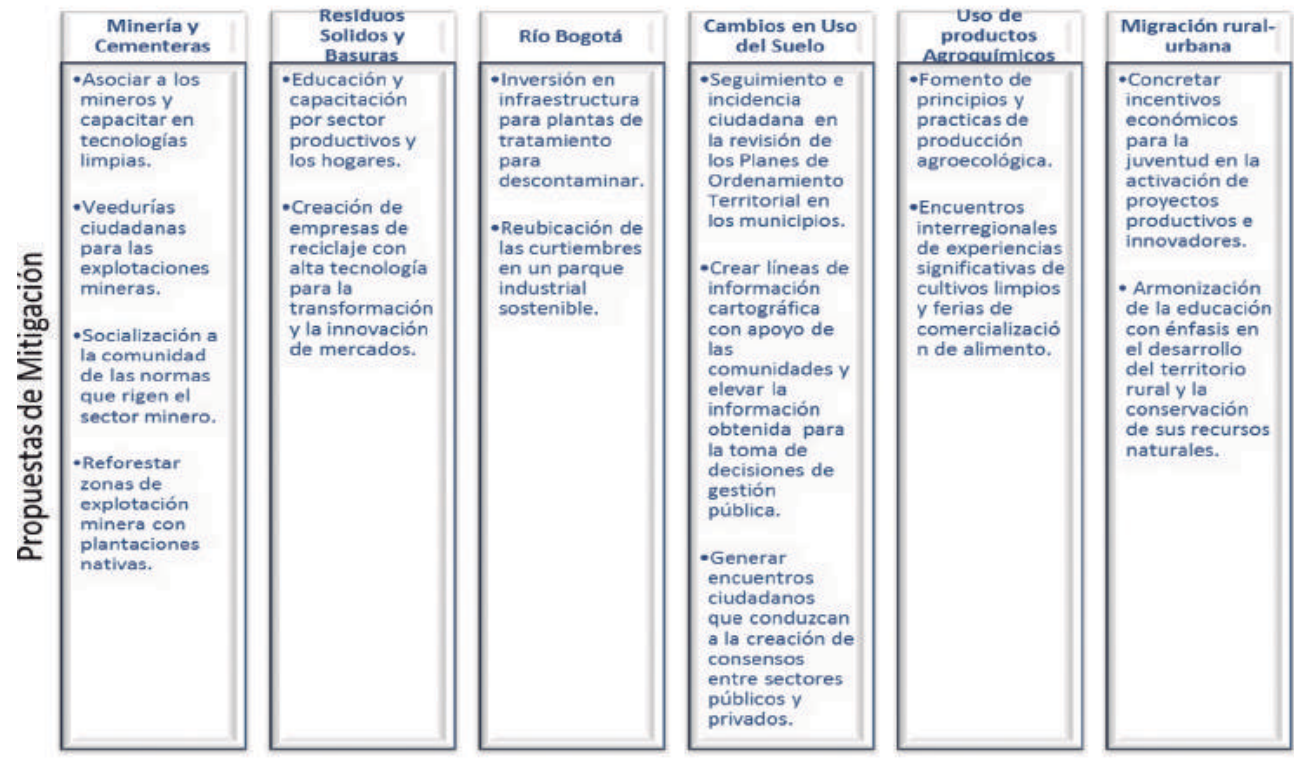

Fuente: esta investigación a partir de Grupo Focal sobre Pactos Territoriales para la mitigación de conflictos por el acceso, uso y regulación de recursos socio-ambientales. Municipio de Sopó, 27 y 28 de junio de 2015.

Figura 8. Lineamientos generales para iniciar un Pacto Territorial.

En definitiva, las iniciativas construidas desde los territorios implicados en los efectos de las prácticas de desterritorialización reclaman la definición de Pactos Territoriales desde los cuales se precisen:

1. La articulación de acuerdos entre actores públicos y comunitarios, pero además con sectores privados, a fin de formalizar procesos de desarrollo local que tengan en cuenta las experiencias acumuladas y las formas de articulación de los actores en el territorio.

2. El mejoramiento de la calidad de vida de los habitantes de las subregiones y contribuir a la reducción de las desigualdades sociales en diferentes ámbitos. Desarrollar la creación de redes para una mejor integración y coordinación de los recursos y de las acciones orientadas a resultados comunes, definidas desde la confianza y la reciprocidad entre los diferentes actores.

3. El diálogo y el intercambio de buenas prácticas a nivel local, nacional e internacional.

Esta apuesta debe contar con todos los actores interesados en el desarrollo y la sostenibilidad de sus recursos (ver Figura 9). En este orden de ideas, las comunidades participantes del estudio 
plantean a su vez una estructura de gestión interinstitucional innovadora sin un orden jerárquico de referencia. En ella aparecen relaciones de vinculación que implican la interlocución entre diversos agentes, que van desde las Secretarías de Planeación de los municipios, hasta los grupos y asociaciones juveniles y de la producción agrícola, pasando por la necesaria interacción con gremios, gobernación departamental, administración municipal, academia y Ministerio del Ambiente. Además, consenso con las pequeñas y medianas empresas (Pymes), industrias e instituciones educativas del nivel básico, tecnológico y superior universitario; asimismo, con los grupos de recicladores, empresas familiares y juntas de acción comunal.

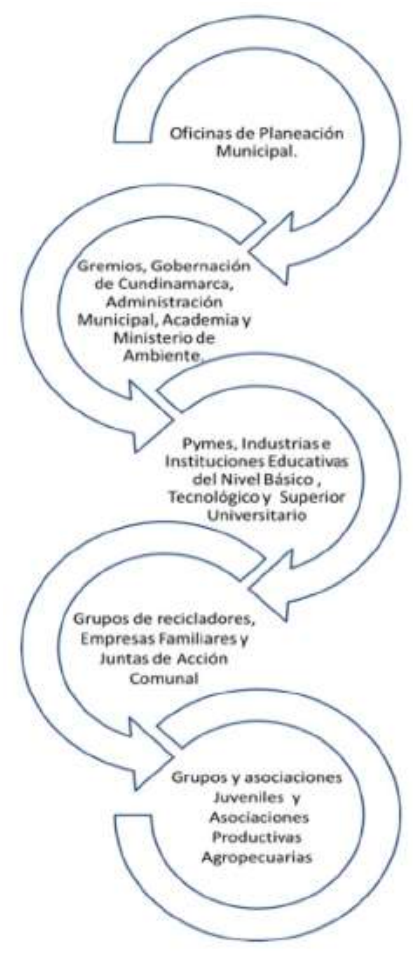

Fuente: esta investigación a partir de Grupo Focal sobre Pactos Territoriales para la mitigación de conflictos por el acceso, uso y regulación de recursos socio-ambientales. Municipio de Sopó, 27 y 28 de Junio de 2015.

Figura 9. Estructura de Agentes Responsables para la Gestión de Pactos Territoriales.

Este modelo de gestión territorial se circunscribe a la intención de romper aquellos pactos sectoriales jerárquicos que normalmente cuentan con la participación de actores relacionados con la focalización de intereses individuales. En este sentido, los Pactos Territoriales deben tener en cuenta: 
De la desterritorialización a la reterritorialización en el acceso, uso y regulación de recursos socio-ambientales...

1. Todos los actores deben ser considerados como iguales, lo que se resume en dar reconocimiento y representación a los grupos sociales no tradicionales, por ejemplo asociaciones, juntas, microempresas, liderazgos innovadores, participación de las mujeres, acciones culturales, educativas, entre otras.

2. Los pactos no debe asumirse desde jerarquías, sino organizados desde los actores participantes.

3. Los participantes deben ser personas y o instituciones con vida jurídica para tomar compromisos y colaborar con los pactos, intercambiando experiencias y técnicas.

4. Activar la participación y movilización social bajo criterios de igualdad y de equidad.

La base de este proceso de gestión debe traducirse en acciones de negociación amplia entre los agentes sociales y los niveles locales, regionales y nacionales de la institucionalidad pública. A manera de procedimiento, la formalización de estos ámbitos para los acuerdos territoriales debe acoger al menos las siguientes etapas:

1. De forma concertada, entre las entidades públicas y comunitarias, la validación y priorización de las propuestas de gestión, que surgen desde los territorios.

2. Definir el pacto territorial, sus objetivos y un cronograma de trabajo.

3. Precisar los costos financieros de los objetivos acordados y definir las estrategias para su acceso o contrapartida.

4. Construir la estrategia y el plan de acción, con los recursos sociales y económicos necesarios para cada una de las partes.

5. Acordar una estructura encargada de la gestión del pacto y el personal puesto a disposición para alcanzar los objetivos territoriales.

6. Definir a los actores que se favorecen con la implementación del pacto y sus responsabilidades generales.

En definitiva, el desarrollo de estas acciones requiere a su vez de una organización de gerencia territorial, componente que debe asumir y garantizar el cumplimiento de los objetivos asumidos, y de evaluar los resultados alcanzados. Esta estructura debe crear e incorporar organismos consultivos locales y otros con trabajos de tipo técnico, operativo y financiero, que apoyen acciones de los comités ejecutivos y del equipo coordinador.

\section{Conclusiones}

Retomando la discusión de contexto y las precisiones conceptuales que soportan este estudio, podemos afirmar que no obstante al poderoso cambio de la matriz productiva, que ha conducido del tránsito de economías tradicionales a prácticas extractivas, el efecto se hace 
notorio en tanto su manifestación en el campo de la desterritorialización de amplios sectores de la sociedad. Asunto que reproduce continuas alteraciones de las relaciones preexistentes en el juego del acceso, el uso y la regulación de recursos socio-ambientales.

Esta condición corrobora la "Tragedia de los Comunes", de la que nos habla Ostrom (2000), asimetrías de conflictividad, que terminan en la expresión de fricciones y antagonismos, en cuyo caso solo queda aparentemente un destino irreversible de deterioro y nula redistribución. Priman allí los desacuerdos y disputas entre los agentes sociales implicados, y quedan de manifiesto emisiones, vertimientos, residuos sólidos, deforestación y fragmentación de hábitats que se reproducen infinitamente a consecuencia del dinamismo de relaciones de poder.

No obstante a ello, cuando se accede a la escala territorial, por fuera de lo estrictamente sectorial, más allá del interés por el crecimiento económico, se reconoce en el sustrato empírico de los agentes sociales, sus organizaciones y estrategias de relacionamiento, la posibilidad de reterritorializar los sistemas sociales y ecológicos de una manera solidaria, cohesionada e innovadora.

Es allí donde cobran sentido las redes sociales. Las prácticas de interacción recogen una perspectiva integradora y contenedora con el medio social y natural. Pero para ello se requiere de la activación y canalización de fuerzas sociales, factores de creación que revelan la capacidad de agenciar acciones y movimientos que superan las tendencias individualizadas, por un nuevo campo de territorialidades que muestra ser un camino más comprensible hacia la sostenibilidad y con ella la inclusión de agentes sociales estratégicos para la gestión del territorio.

En este orden de ideas, se hace de vital importancia avanzar hacia la materialización de Pactos Territoriales para definir ámbitos colaborativos entre el Gobierno u otras entidades públicas, además de los propios sectores comunitarios.

En síntesis, los hallazgos obtenidos en este estudio tienen como fin generar una comprensión al agenciamiento local como factor vinculante entre el territorio, la participación y la sostenibilidad de los recursos colectivos. Permiten aproximarnos, parafraseando a Davoudi (2007), al conjunto de acciones colectivas que se proyectan mediante formas de gobernanza territorial, entre los agentes sociales inmersos en su configuración y el reconocimiento de aquellos factores del contexto local y regional para alcanzar incentivos que promuevan una estructura de calidad en las redes institucionales oficiales, además de las convenciones, rutinas y hábitos enraizados en las localidades que se han mantenido por largo tiempo. 
De la desterritorialización a la reterritorialización en el acceso, uso y regulación de recursos socio-ambientales...

\section{Referencias}

Abramovay, R. (2003). O capital social dos territórios: repensando o desenvolvimento rural. En R. Abramovay (Ed.), O futuro das regiões rurais (pp. 83-100). Porto Alegre, Brasil: UFRGS.

Abramovay, R. (2006). Para una teoría de los territorios sociales. En M. Manzanal, G. Neiman y M. Lattuada (Comps.), Desarrollo, Instituciones y Territorio (pp. 51-70). Buenos Aires, Argentina: Centro Integral Comunicación, Cultura y Sociedad -CICCUS-.

Borgatti, S. (2003). Conceptos básicos de redes sociales. Recuperado de http: / / grupos.emagister. com/documento/conceptos_basicos_de_redes_sociales/1045-14271

CAR. (2006). POMCA Río Bogotá. Bogotá, Colombia: Corporación Autónoma Regional de Cundinamarca.

CAR. (2007). Atlas Ambiental CAR 50 años. (Primera Ed.). Bogotá, Colombia: Corporación Autónoma Regional de Cundinamarca.

CAR. (2011). Informe de Gestión 2010. Bogotá, Colombia: Ministerio de Ambiente y Desarrollo Sostenible.

CAR. (2012). Plan de Gestión Ambiental Regional. PGAR 2012- 2023. Bogotá, Colombia: Car

Davoudi, S. (2007). Cohesión territorial: relaciones con la planificación territorial y la política regional. En J. Farinós y J. Romero (Eds.), Territorialidad y buen gobierno para el desarrollo sostenible. Nuevos principios y nuevas políticas en el espacio Europeo (pp. 67-77). Valencia, España: Universidad de Valencia.

Deleuze, G. y Guattari, F. (2004). Mil Mesetas. Capitalismo y esquizofrenia. Valencia, España: Editorial Pre-textos.

Folchi, M. (2001). Conflictos de contenido ambiental y ecologismo de los pobres: no siempre pobres, ni siempre ecologistas. Ecología política, 22, 79-100.

Giddens, A. (2003). La Constitución de la sociedad. Bases para la teoría de la estructuración. Buenos Aires, Argentina: Amorrortu editores.

Haesbaert, R. (2011). El mito de la desterritorialización:del fin de los territorios a la multiterritorialidad. Ciudad de México, México: Siglo XXI Editores.

IGAC. (2007). Atlas de Cundinamarca. Bogotá, Colombia: Instituto Geográfico Agustín Codazzi.

Jiménez, L. (2002). La sostenibilidad como proceso de equilibrio dinámico y adaptación al cambio. Recuperado de http://www.revistasice.info/cachepdf/ICE_800_6584_9104052062A 6C18EDC01F0D7CB42BC1E.pdf 
Leff, E. (2004). Racionalidad ambiental. La reapropiación social de la naturaleza. Recuperado de http: / / aao.org.br/aao/pdfs/publicacoes/racionalidad-ambiental-enrique-leff.pdf

López, T. (Ed.). (2008). Teoría básica del conflicto. Unidad 1: Capacitación y desarrollo internacional. Recuperado de http://www.visiondiweb.com/insight/lecturas/Teoria_basica_del_ conflicto.pdf

Mançano, B. (2014). Territorios: teoría y disputas por el desarrollo rural. Recuperado de http: / /www.cedem.uh.cu/sites/default/files/116-133.pdf

Naredo, J. (2010). Raíces económicas del deterioro ecológico y social. Más allá de los dogmas. Madrid, España: Editorial Siglo XXI.

Pérez, M. (2011). Tendencias Interpretativas en la Concepción y Gestión del Desarrollo Rural. Recuperado de http: / / www.rimisp.org/FCKeditor/UserFiles/File/documentos/docs/ sitiopobrezarural/documentos/Documento-dicusion-Concepcion-gestion-desarrollorural-Manuel-Perez.pdf

Ostrom, E. (2000). El gobierno de los bienes comunes. La evolución de las instituciones de acción colectiva. Ciudad de México, México: UNAM-CRIM-FCE.

Raffestin, C. (2011). Por una geografía del poder. Ciudad de México, México: El Colegio de Michoacán.

Sepúlveda, S. (2008). Gestión del desarrollo sostenible en territorios rurales: métodos para la planificación. Recuperado de http://www.territorioscentroamericanos.org/ experiencias/Documents/Planificaci\%C3\%B3n\%20y\%20Gesti\%C3\%B3n\%20de\%20 Territorios.pdf

Strange, S. (1996). The Retreat of the State:The Diffusion of Power in the World Economy. New York: Cambridge University Press.

Walter, M. (2009). Conflictos ambientales, socio-ambientales, ecológico-distributivos, de contenido ambiental. Reflexionando sobre enfoques y definiciones. Boletín Ecos, 6. Recuperado de http://www.justiciaambiental.org/wp-content/ uploads/2016/08/2009_conflictos_ambientales_enfoques_definiciones.pdf

Williner, A., Sandoval, C., Frias, M. y Pérez, J. (2012). Redes y pactos sociales territoriales en América Latina y el Caribe: sugerencias metodológicas para su construcción. Santiago de Chile, Chile: Instituto Latinoamericano y del Caribe de Planificación Económica y Social (ILPES). 